\title{
Tratado da esfera
}

\section{JOÃO DE CASTRO}

Discípulo - De que substância são os ceos? Elles parecem de cristal ou doutra cousa semelhante.

Mestre - São de huma substância mais excellente que todo o cristal, e todo diamão, e todo metal, e toda pedra preciosa, por que, em fim, todas essas cousas de preço sam corruptiueis e todas suas virtudes se acabão com ellas; mas os ceos sam de huma substância incorruptiuel e totalmente inuiolavel, perpetuos, e suas virtudes durrão para sempre. À substância dos ceos chama Aristoteles a quinta substância, quinta-essência porque não he nenhuma da dos quatro elementos , mas he outra substância simples acima delles, muyto mais excellente, sem comparação com todos elles, porque não tem em si algumas calidades contrairas, nem as podem receber de fora; de maneira que não são pesados, nem leues, nem moles, nem duros, nem são quentes, nem frios, nem humidos, nem secos, nem se podem aquentar, nem esfriar, humedecer, nem secar; finalmente, de nenhuma alteraçam, nem calidade contraira sam capazes. Esta he a causa por que não hay força em todo mundo, nem virtude natural que os possa penetrar, nem corromper, inda que sejão tiros de bombardas. (...)

D. - Ja que auemos de tratar da região elemental, primeiramente queria saber a causa deste nome, e por que se chama assi esta parte do mundo inferior da lua pera baixo. Também folgaria de entender logo no principio que cousa ha que saber nos elementos.

M. - Quanto ao nome, pera guardar boa ordem, delle deuemos de começar. Chamase região elementar por que contem em si os quatro elementos, s., terra, agoa, ar e fogo.

D. - Por que se chamão elles elementos? Que quer dizer este nome?

M. - A propria significação delle he principio, por que cada elemento he principio das cousas naturais; e com muita razão se chamão os elementos principios, por que destes quatro principios se compõem todas quantas cousa naturais se gerão e corrompem no mundo; donde he muyto pera considerar a grande sabedoria de Deos, que tantas e tam várias temperas sabe dar a estes quatro elementos, que delles faz todas quantas cousas no mundo se gerão e corrompem. Quem não pasmaria se visse hum official tão sapiente, que a tres ou quatro materiais soubesse dar tantas e tam boas temperas; que quando delles quisese fazer ouro, lhe saysse ouro, e quando quisesse ferro, lhe saisse ferro, e quando quisesse prata, prata; e, finalmente, dali tirasse todo genero de metais e de cousas que quisesse? Pois quanto mais he pera pasmar ver o autor da natureza ser tam sabio e tão excellente official de suas cousas naturais, que de quatro principios elementais sabe fazer tantas e tam boas misturas, e tirar dellas tanta variedade de cousas; e o que mais he, que em qualquer mistura, fazendo aos elementos perder suas formas essenciaes, lhes faz de si lançar outra $3^{a}$ forma qualquer que elle pretende: se quer metais ou pedraria, lanção os elementos de si a forma de metal ou pedra preciosa pera que os temperou; se quer aruores ou plantas, em tendo a materia pera isso desposta, lanção de si a forma de qualquer aruore ou planta que elle quis; se quer animais que viuão, lanção de si as formas de quaisquer viuentes que elle pertendeo; e isto com várias temperas e disposições, e as vezes com muitas transformacões; todavia nenhuma matéria, por mais temperas e desposições que tenhão, pode lançar de si a forma do homem; por ser cousa immortal e aeterna, esta cria Deus de nouo, e a lança do ceo quando a matéria esta pera ella totalmente desposta. Quanto as cousas que dos elementos se podem por agora dizer sam

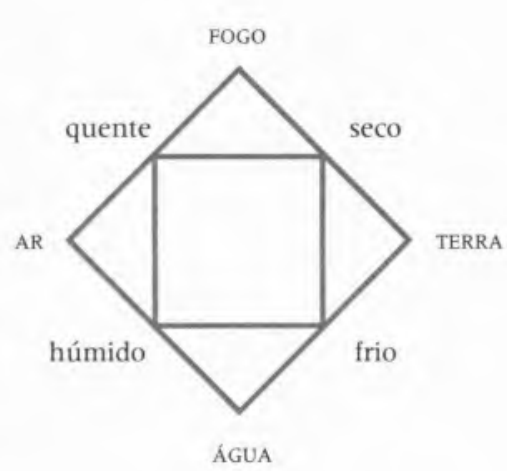

As quatro qualidades e os quatro elementos

várias, nem se pode facilmente reduzir a certo número; somente o que em geral diremos com breuidade, sera o número, calidades, ordem e figura dos elementos; e depois de cada hum em particular se dirão diversas cousas.

D. - Quantos sam os elementos, e que calidades tem?

M. - Neste universo (como ia dissemos) a hi quatro corpos elementaes: tem cada hum duas calidades, huma, como sua propria, em grao intenso, outra, menos propria, em grao remiso, em que combina e participa com outro elemento; a terra he seca de sua natureza em summo grao, e fria em grao remiso; agoa fria em grão intenso, e humida em remiso; o ar humedo em grao intenso, e quente em remiso; o fogo quente intensamente, com secura remisa.

D. - Da ordem e figuras dos elementos, que ahy que dizer?

M. - Não ha mais que dizer senão que todos tem figura redonda, de maneira que a terra, posta bem no meio, tem o mais infimo lugar de todo mundo; a agoa cerra e abraça a terra; o ar encerra e abraça dentro em si toda a agoa e terra; o fogo, da mesma maneira, fecha e rodea por todas as partes o ar e os demais elementos inferiores.

D. - Cada elemento superior quanto he maior que o inferior?

M. - Diz Aristoteles que em decupla proporção; dos quais isto baste em comum. 


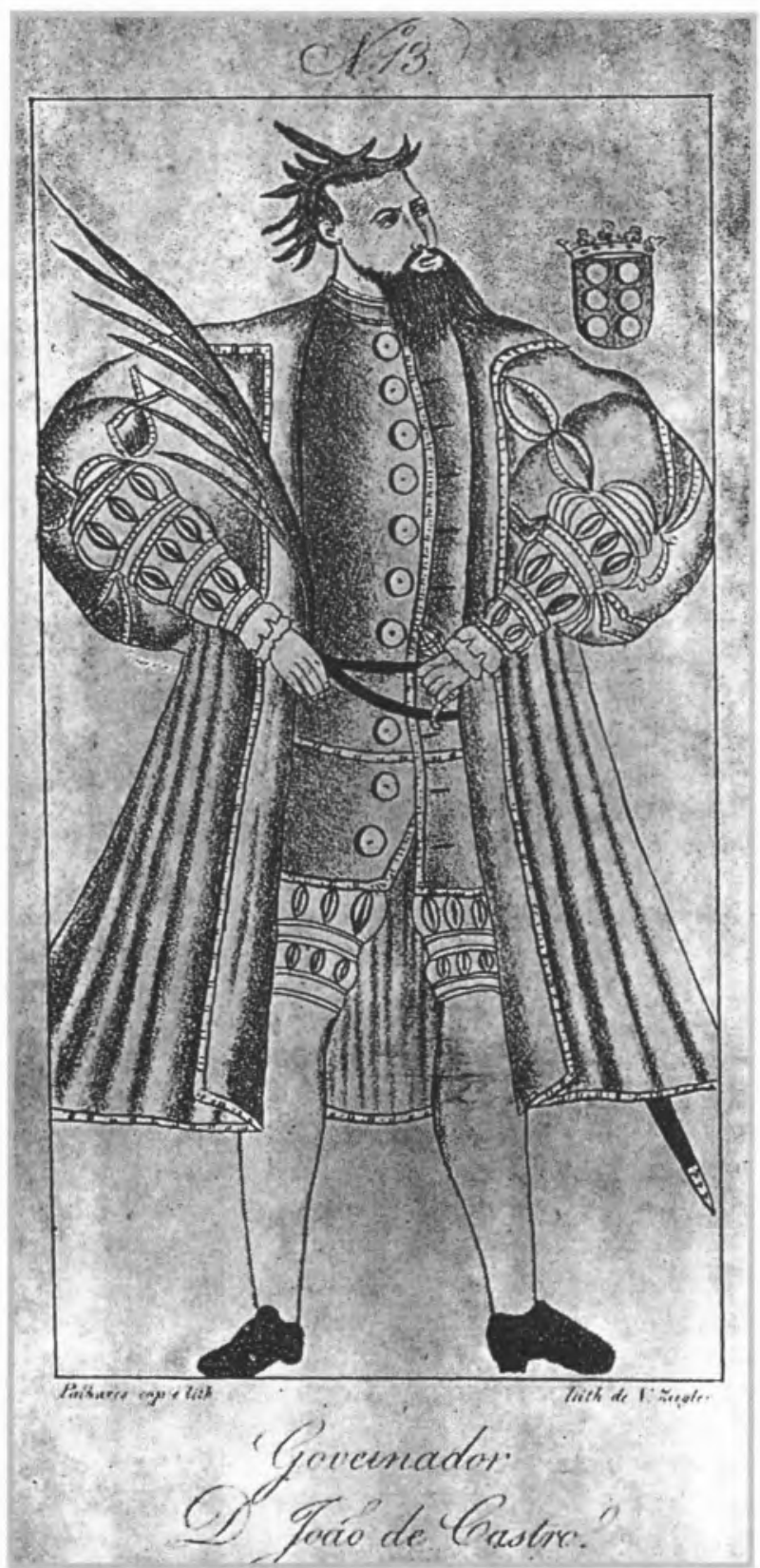

Retrato de D. João de Castro, executado por Gaspar Corrêa para a Galeria dos Governadores no Palácio de Goa

\section{DA TERRA}

D. - De qual dos elementos auemos de comecar?

M. - Assi como na região coelestial começamos do mais baixo ceo, que he o da lua, assi na região elemental começaremos do mais baixo elemento, que he a terra.

D. - Deseio saber da terra, pois he elemento simplez, se está em sua pureza natural.

M. - A terra, aynda que foi criada de Deus no principio pura e sem mestura de outro elemento, todavia Deus N.S. não quis que ficasse assi pura e em sua natureza, por que dessa maneira não seruia pera o que Deos nella pretendia, que he habitação do genero humano e a criaçam dos outros animaes, e pera geração das prantas, eruas e todas as cousas que por toda a terra se produzem.

D. - Por que rezão em seu puro natural não seruia nem pera habitação dos homens nem pera a criaçam das demais cousas ?

M. - Por que, como temos dito, he de seu natural a terra seca em summo grau, pela qual rezão, se fora deixada em sua natureza, ouuera de ser mais seca que poo de cinza ou de cal; assi, (por) que dessa maneira era inutil pera toda habitação e criaçam, Deus N.S. a mesturou com a agoa, e assi mesturada não fiqua elemento puro, mas fica habitada e frutuosa, não tão somente pera criar em si todo o genero de animaes, prantas e verduras e todos os mantimentos, senão ainda ouro, prata e todo genero de metaes.

D. - Se o elemento da agoa he dez uezes tamanho como a terra, e a terra he mais piquena sphaera de todos os elementos, e esta posta no meio dellas, por que rezão não esta toda cuberta de agoa?

M. - Naturalmente ella assi deuera de estar cercada por todas as partes, e cuberta de agoa, se o elemento da agoa estiuera em sua cantidade e proporção natural; e assi esteue no principio, quando Deus criou o mundo, atee que mandou que se congregassem as agoas em hum lugar, e que aparecesse a terra; donde parece quam bem atinou Aristoteles com a grandeza e proporção natural que os elementos auião de ter huns sobre os outros; mas enganou se ou enliou se com o elemento da agoa por não ter noticia da criacção do mundo nem da congregação das agoas, com a qual o criador e autor da natureza as deminuyo, e ficarão em menos quantidade que a natural.

D. - Como pella congregaçam se deminuirão estas agoas?

M. - Per duas uias, a primeira, principal, por que sendo dantes muy raras, se condensarão e ficarão em muito menos quantidade; e oura por que grande parte dellas se embebeo na terra. (...)

D. João de Castro, in:

Tratado da Esfera por Perguntas e Respostas, ca. 1535. 